\title{
What cognitive science says about how students learn
}

\section{Timothy Slater}

Timothy F. Slater, "What cognitive science says about how students learn," Proc. SPIE 9663, Eighth International Topical Meeting on Education and Training in Optics and Photonics, 96631R (6 October 2003); doi: $10.1117 / 12.2208474$

SPIE Event: Eighth International Topical Meeting on Education and Training in Optics and Photonics, 2003, Tucson, Arizona, United States 


\title{
What cognitive science says about how students learn
}

\author{
Timothy F. Slater \\ University of Arizona, 933 N. Cherry Ave, Tucson, AZ,85721 \\ telephone: 520-621-7096; fax: 520-621-1532; e-mail: tslater@as.arizona.edu
}

\begin{abstract}
Over the last two decades, there has been substantial effort by scientists on understanding how students learn science. Systematic research shows that effective instruction builds specifically on students' prior knowledge and provides multiple opportunities for meaningful feedback in novel settings.

(C)2003 Optical Society of America

OCIS codes: (000.2060) Education; (000.2700) General science
\end{abstract}

Over the last two decades, the scientific community has witnessed an explosive growth in the number of scientists who are adopting research in teaching and learning as their principal area of academic scholarship. In particular, recent national conferences of the American Association of Physics Teachers (AAPT) have seen tremendous growth in physics education research (PER) presentations and PER participation go from being barely visible to dominating many conference attendees' schedules. The AAPT, with leadership from the PER community, is even publishing Physics Education Research - A Supplement to the American Journal of Physics to serve this community. Some of the recent results resulting from this flurry of activity have significant implications for teaching introductory science.

A cornerstone to a constructivist approach to instruction is to identify and confront students' initial ideas about the world. In years past, faculty have looked at students as tabla rasa-the idea that students enter the introductory science course as "blank slates" on which knowledge can simply be written (Mestre, 1991, Mestre \& Touger, 1989). Although certainly not the first nor the most comprehensive study, the most public demonstration of how initial ideas can interfere with instruction was presented in the video "Private Universe" produced by Philip Sadler and his colleagues at Harvard. In this video, both Harvard college graduates and middle school students are asked to describe the reason for the seasons and the cause of Moon phases and they perform, to most viewers' great surprise, very poorly. This provocative video then goes on to show that how instruction that does not adequately consider initial student ideas is unsuccessful in altering those ideas. Recently additional videos have been made on optics as well.

We now understand that if students are going to abandon their self-formed and scientifically inaccurate ideas, they must not only be dissatisfied by the current knowledge, but the new knowledge must fit with other existing ideas and be more productive in terms of understanding a wide range of phenomena (Posner, Strike, Hewson and Gertzog, 1982). Otherwise, new ideas presented in class will not be successfully integrated into existing knowledge, will not be easily accessed when required, and even if memorized for the exam will be quickly abandoned afterwards. This applies no matter how clearly the lecturer describes the concept. This recognition has lead faculty and PER researchers to develop teaching strategies, often known as "cognitive change" strategies, that illicit student ideas, confront student ideas to help students see inconsistencies, and guide students to build accurate ideas that resolve these inconsistencies. Although not the only pedagogical approach to address issues of cognitive change, this is the approach that has been used most widely in recent reforms of physics and astronomy curriculum and is one that can lead to demonstrably better student learning. 